\title{
Dual staining with CFDA-AM and SYTOX Blue in flow cytometry analysis of UV-irradiated Tetraselmis suecica to evaluate vitality
}

\author{
Ranveig Ottoey Olsen ${ }^{1}$, Ole-Kristian Hess-Erga ${ }^{2}$, Aud Larsen ${ }^{3}$, \\ Friederike Hoffmann ${ }^{4,5}$, Gunnar Thuestad ${ }^{1}$, Ingunn Alne Hoell ${ }^{1, *}$ \\ ${ }^{1}$ Stord/Haugesund University College, Bjoernsonsgt. 45, 5528 Haugesund, Norway \\ ${ }^{2}$ Norwegian Institute for Water Research, Thormoehlensgt. 53 D, 5006 Bergen, Norway \\ ${ }^{3}$ Uni Research Environment and Hjort Centre for Marine Ecosystem Dynamics, 5006 Bergen, Norway \\ ${ }^{4}$ Uni Research Environment, Thormoehlensgt. 49 B, 5006 Bergen, Norway \\ ${ }^{5}$ University of Bergen, PO Box 7800, 5020 Bergen, Norway
}

\begin{abstract}
After disinfection of ballast water, it is crucial to detect organisms and determine their vitality to assess the performance of the chosen treatment technique. Ultraviolet (UV) irradiation is a treatment technology commonly used for water disinfection. In this study, the phytoplankter Tetraselmis suecica was UV irradiated and subsequently stained with both 5-carboxyfluorescein diacetate acetoxymethyl ester (CFDA-AM) and SYTOX Blue, staining metabolically active and membrane-permeable cells, respectively. This dual staining protocol can be used to assess samples during type approval of UV-based treatment systems. Non-irradiated and UV-irradiated samples were incubated in darkness, to simulate a ballast water transport, after which the vitality and viability $T$. suecica were monitored regularly over a period of $15 \mathrm{~d}$. Flow cytometry (FCM) analysis separated the cells into 4 FCM populations (=single cells grouped together based on their fluorescence signals) according to differences in esterase activity and membrane integrity. UV-irradiated samples followed a different staining pattern compared to non-irradiated samples, where 1 specific FCM population of cells expressed esterase activity, but at the same time gave signals for disrupted membranes. This is useful as a sign of future death and is interpreted as an 'early warning' FCM population. FCM results were also compared to corresponding plate count results, differentiating vital, viable cells from vital, non-viable cells. We argue that dual staining with SYTOX Blue and CFDA-AM facilitates and improves FCM analysis when evaluating the performance of UV-based water treatment systems.
\end{abstract}

KEY WORDS: Phytoplankton - Ballast water $\cdot$ Water treatment $\cdot$ Live/dead analysis $\cdot$ Viability · Water analysis

\section{INTRODUCTION}

Live/dead analysis of organisms in disinfected water, such as from ballast water treatment systems (BWTS) or aquaculture-, drinking-, and wastewater applications, is crucial to determine the efficiency of the treatment technique. Disinfection can be performed with chemical (e.g. chlorination, ozonation, and electrolysis) and/or physical (e.g. ultraviolet

\footnotetext{
*Corresponding author: ingunn.hoell@hsh.no
}

[UV] irradiation, heat, and cavitation) treatment technologies (Shannon et al. 2008, Werschkun et al. 2012, 2014). Traditionally, water analysis used to assess most treatment technologies has depended on cultivation, such as the plate count or the most probable number (MPN) technique. Cultivation methods measure viability of organisms present, i.e. the ability of a cell to reproduce. Vital (live) cells can be either viable or non-viable, whereas non-vital (dead)

() The authors 2016. Open Access under Creative Commons by Attribution Licence. Use, distribution and reproduction are unrestricted. Authors and original publication must be credited. 
cells are non-viable. Cultivation methods can be time-consuming and may give false negatives, as several species are unable to grow under laboratory conditions, or they can be in a viable but non-culturable state (Staley \& Konopka 1985, Roszak \& Colwell 1987). Problems related to cultivation methodology can be circumvented by studying populations and communities indirectly, e.g. by determination of biological material or activity using flow cytometry (FCM), epifluorescent microscopy, photometer, luminometer, or DNA/RNA based methods. FCM facilitates rapid detection, enumeration, and characterization of organisms when combined with fluorescent dyes. Fluorescent dyes are molecules that label microbes or cellular constituents according to their biochemical, physiological, or taxonomic characteristics, and that can fluoresce upon light excitation (Shapiro 1983, 2000, Spence \& Johnson 2010).

Staining technology for live/dead evaluation of cells is largely based on 2 physiological characteristics: membrane integrity and metabolic activity. Commonly used stains to assess membrane integrity are propidium iodide (PI) and SYTOX Green (Veldhuis et al. 1997, Berney et al. 2007, Peperzak \& Brussaard 2011). These non-fluorescent stains enter cells when membrane integrity is lost and fluoresce when bound to nucleic acids, while they are excluded from cells with intact membranes. Permeabilized cells are usually characterized as dead because they are unable to maintain the membrane potential and hence their intracellular environment (Joux \& Lebaron 2000, Kroemer et al. 2009, Hammes et al. 2011). The Nomenclature Committee on Cell Death has proposed criteria to evaluate a cell as dead; one of these is loss of cell membrane integrity (Kroemer et al. 2009). Esterases are cellular housekeeping enzymes indicative of the presence of metabolic activity. Esterase substrates, like fluorescein diacetate (FDA) and carboxyfluorescein diacetate (CFDA), can be used to evaluate this activity (Bentley-Mowat 1982, Dorsey et al. 1989). The non-fluorescent substrate freely diffuses across membranes and is hydrolyzed by unspecific intracellular esterases. The fluorescent product is retained in cells with intact membranes, and the fluorescence intensity is correlated with the metabolic activity. Esterase substrates are commonly used in FCM studies of phytoplankton (Garvey et al. 2007, Steinberg et al. 2011, Gorokhova et al. 2012, Peperzak \& Gollasch 2013, Olsen et al. 2015).

Previously, we developed an FCM protocol to discriminate dead Tetraselmis suecica from live and UV damaged cells (Olsen et al. 2015). Prior to FCM analysis, the alga was stained with CFDA-acetoxy- methyl ester (CFDA-AM), which is hydrolyzed to carboxyfluorescein in esterase active cells. When UV irradiated, some $T$. suecica cells still remained esterase active even though their viability was lost, as has also been observed for bacteria and yeast (Schenk et al. 2011, Kramer \& Muranyi 2014).

Staining with 2 or more fluorescent dyes can facilitate measurements of multiple cellular characteristics simultaneously. When combining FDA and PI, cells are stained according to their enzyme activity and their permeability, respectively. For UV-C treated Listeria innocua, combining FDA and PI stains revealed a subpopulation that retained esterase activity at the same time that the membrane integrity was lost (Schenk et al. 2011). PI has an emission maximum $(636 \mathrm{~nm})$ in the same area as chlorophyll when excited with a blue $(488 \mathrm{~nm}$ ) laser; hence PI fluorescence cannot be detected in the same detector as chlorophyll-containing organisms (phytoplankton). Yet, high concentrations of PI $(7.5-120 \mu \mathrm{M})$ have been applied to Microcystis aeruginosa and diverse algal species in some studies, detecting orange fluorescence in the 560-600 nm area (Franklin et al. 2001, Xiao et al. 2011). However, it is not feasible to use PI and esterase substrates simultaneously, since emission partly overlaps. SYTOX Green (emission maximum $523 \mathrm{~nm}$ ) has previously been used to assess UV-irradiated phytoplankton (Martínez et al. 2012, Steinberg et al. 2012), but its fluorescence interferes with fluorescence from CFDA-AM (emission maximum $535 \mathrm{~nm}$ ) and combining the two is thus not useful. Instead, SYTOX Blue (emission maximum $480 \mathrm{~nm}$ ), which enters cells with permeabilized membranes and binds to nucleic acids just like SYTOX Green, was combined with CFDA-AM. Together they facilitate separation of the fluorescence signals based on esterase activity and membrane integrity.

Using UV irradiation as a disinfection technology can induce structural changes to the genetic material in cells and cause impairment of replication (Sinha \& Häder 2002). UV irradiation can also affect other biological molecules and induce formation of reactive oxygen species (ROS) in bacteria and algae, causing oxidative damage to lipids, proteins, and DNA (Kalisvaart 2001, Bosshard et al. 2010, Kottuparambil et al. 2012, Santos et al. 2012, 2013, Kramer \& Muranyi 2014). As a response, organisms have various mechanisms to prevent and counteract the damage, including DNA repair mechanisms (Sinha \& Häder 2002). Such responses, which occasionally cause damaged cells to recover after treatment, lead to challenges for viability evaluations. Moreover, when analyzing disinfected water, the terms describing 
cellular status can cause confusion, e.g. 'active'/ 'inactive', 'live'/'dead,' and 'viability.' For instance, since metabolic activity in a cell varies depending on cellular condition, the metabolic activity in a cell is correlated with the fluorescence intensity from esterase substrates, and the fluorescence signal will vary accordingly (Bentley-Mowat 1982, Dorsey et al. 1989, Murphy \& Cowles 1997, Brookes et al. 2000). Membrane permeability can be reversed or may just occur as a temporary condition (Shi et al. 2007), which can cause difficulties for vitality indications when using stains to assess membrane integrity, like PI and SYTOX Blue. Moreover, for ballast water discharge, the International Maritime Organization (IMO) Convention refers to the 'viable' organisms (IMO 2004); however, the guidelines for approval of ballast water management systems (G8) define viable organisms as 'organisms and any life stages thereof that are living' (IMO 2008, p.7). The US Coast Guard (USCG) also make use of the term 'living' (USCG 2012).

The aim of the study was to improve our previously developed FCM protocol (Olsen et al. 2015) to evaluate the performance of UV-based water treatment techniques and overcome the challenges described above. In order to do so, we aimed at answering the following questions:

(1) Will dual staining of $T$. suecica using CFDA-AM and SYTOX Blue yield fluorescent signals based on esterase activity and membrane integrity suitable for differentiating cells into FCM populations reflecting cellular vitality?

(2) Can the fluorescent signals from dual-stained cells (SYTOX Blue and CFDA-AM) be used to predict future death?

(3) Is dual staining with SYTOX Blue and CFDAAM recommendable for evaluation of live and viable T. suecica for ballast water monitoring in compliance with the IMO and USCG regulations?

\section{MATERIALS AND METHODS}

\section{Experimental set-up}

The phytoplankter Tetraselmis suecica (Strain K0297) was obtained from the Scandinavian Culture Collection of Algae and Protozoa (University of Copenhagen, Denmark) and cultured in $36 \mathrm{~g} \mathrm{~kg}^{-1}$ artificial sea water (ASW) (Marine SeaSalt) supplemented with $0.12 \%$ Substral (The Scotts Company [Nordic]). Incubation was performed in light at $36 \mathrm{~W} \mathrm{~m}^{-2}$ (corresponding to $173 \mu \mathrm{mol} \mathrm{m}{ }^{-2} \mathrm{~s}$ of photosynthetically active radiation photons) at $15^{\circ} \mathrm{C}$ and $1.7 \mathrm{~cm}$ orbital shaking at $100 \mathrm{rpm}$. The culture was further diluted with growth medium to a concentration of $10^{4}$ cells $\mathrm{ml}^{-1}$ prior to UV treatment. The cell concentration was detected by FCM.

To inactivate the algae, a collimated medium pressure (MP; $800 \mathrm{~W}$ ) UV lamp (BestUV) with a polychromatic (200-400 nm) mercury lamp was used (Olsen et al. 2015). The UV-C intensity was $0.525 \mathrm{~mW} \mathrm{~cm}^{-2}$, and the weighted average germicidal factor, based on the absorbance spectrum of DNA from Bacillus subtilis (Chen 2009), was 0.5799.

A $45 \mathrm{ml}$ aliquot of diluted $T$. suecica was irradiated in a petri dish while being mixed with a magnetic stir bar (150 rpm) at room temperature (RT). The exposure times were $180,359,539,718$, and $1436 \mathrm{~s}$ for UV doses 100, 200,300,400, and $800 \mathrm{~mJ} \mathrm{~cm}^{-2}$, respectively. The lowest UV dose is comparable to those used in BWTS, but ballast water is treated twice (on uptake and discharge). UV doses between 400 and $800 \mathrm{~mJ} \mathrm{~cm}^{-2}$ were not applied, since previous FCM studies showed that CFDA-AM-stained T. suecica

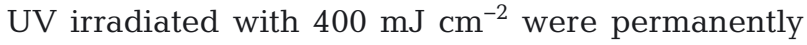
inactivated (Olsen et al. 2016). Doses of 400 and $800 \mathrm{~mJ} \mathrm{~cm}^{-2}$ were both included in the study to examine whether and how esterase activity and membrane integrity differed in these samples. Three subsamples were prepared for each UV dose, irradiated in $2 \mathrm{~h}$ intervals, and subsequently transferred to $50 \mathrm{ml}$ Falcon conical centrifuge tubes (Fisher Scientific). Non-irradiated cells (controls, $2 \times 45 \mathrm{ml}$ ) and dead cells $(8.5 \mathrm{ml})$ fixed with formaldehyde $(5 \%$ final concentration; 36.5-38\%, Sigma-Aldrich) were also transferred to tubes. All tubes were wrapped in aluminum foil and incubated with loosened lids at $15^{\circ} \mathrm{C}$ in the dark to simulate a dark ballast water transport up to $15 \mathrm{~d}$, with samples collected at several time points.

\section{Analysis}

The cells were stained with the esterase substrate CFDA-AM (C1354, Thermo Fisher Scientific) and SYTOX Blue Dead Cell Stain (S34857, Thermo Fisher Scientific) prior to FCM analyses. Aliquots of 10 and $1 \mathrm{mM}$ CFDA-AM and SYTOX Blue, respectively, in dimethyl sulfoxide were kept at $-20^{\circ} \mathrm{C}$. Work solutions of CFDA-AM (1 mM) and SYTOX Blue $(0.3 \mathrm{mM})$ were prepared fresh each day by diluting with Milli-Q water. The samples were first stained with CFDA-AM to a final concentration of $2000 \mathrm{nM}$, and incubated for 50 min at RT under dark 
conditions (Ganassin et al. 2000, Olsen et al. 2015). Although no data addressing the toxicity of SYTOX Blue was available from the manufacturer (Molecular Probes), they recommended staining in the range of 625 to $10000 \mathrm{nM}$. Optimal concentration and incubation time for SYTOX Blue was therefore determined in advance; SYTOX Blue was added to the samples at a final concentration of $2000 \mathrm{nM}$ and further incubated for $10 \mathrm{~min}$ at RT in the dark. Note that SYTOX Blue was added last (after CFDA-AM) to avoid potential harmful effects. The samples were analyzed by FCM immediately after the incubation period (60 min).

FCM analysis was performed on an Attune Acoustic Focusing Cytometer (Thermo Fisher Scientific) equipped with a $20 \mathrm{~mW} 488 \mathrm{~nm}$ (blue) laser exciting CFDA-AM and chlorophyll a (chl a), and a $50 \mathrm{~mW}$ $405 \mathrm{~nm}$ (violet) laser exciting SYTOX Blue. The BL1 (530/30), VL1 (450/40), and BL3 (640LP) detectors were used for detection of green, blue, and red fluorescence from CFDA-AM, SYTOX Blue, and chl $a$, respectively. Additionally, forward and side scatter from the blue laser were detected. The trigger was set to red fluorescence (BL3 detector), the threshold to 60000 , and the voltage of the forward and side scatter, BL1, VL1, and BL3 detectors to 300, 1300, 1100,1200 , and 1300, respectively. Compensation is the mathematical method used to correct the overlap of one fluorophore's emission into another fluorophore's emission channel. However, emission of CFDA-AM into the VL1 channel, and SYTOX-Blue into the BL1 channel, were both low, and compensation corrections were therefore not performed. Emission overlap did not occur because the stains were excited with different lasers and have separate emission areas. One $\mathrm{ml}$ of each sample was analyzed at a flow rate of $1000 \mu \mathrm{min}^{-1}$ at standard sensitivity. Control samples included were: (1) non-irradiated cells both unstained and dual stained and (2) dead cells killed using formaldehyde followed by the dual staining procedure. The dead stained cells were not expected to fluoresce either green or blue, but red. The cells were not esterase active or permeabilized, but were previously shown to retain their red fluorescence $24 \mathrm{~d}$ after formaldehyde treatment (Olsen et al. 2015).

In order to determine culturability (i.e. viable cells) by the number of colony-forming units (cfu), samples were cultured on 1\% Bacto ${ }^{\mathrm{TM}}$ Agar (Difco Laboratories, Becton-Dickinson) in 24 ppt ASW supplemented with $0.12 \%$ Substral. The agar plates were incubated in light at $36 \mathrm{~W} \mathrm{~m}^{-2}$ at $15^{\circ} \mathrm{C}$ for $3 \mathrm{wk}$. The number of cfu for each plate was determined, and the mean values of the 3 replicates were calculated. Regression analysis for plate counts and FCM results were performed in Microsoft Excel 2010.

FCM and plate counts were performed on Days 0 (4 h), 1, 2, 3, 4, 7, 10, and 15 after dark incubation. At the beginning of the experiment, the volume of each sample was $45 \mathrm{ml}$. On each analysis day, a total of $3.6 \mathrm{ml}$ from each sample were removed for FCM analysis and plate counts. At the end of sampling, the volumes of each sample were reduced from 45 to $16 \mathrm{ml}$.

\section{RESULTS}

\section{FCM analysis of dual-stained Tetraselmis suecica}

The FCM signals from $T$. suecica cells unstained and dual stained with CFDA-AM and SYTOX Blue are presented as dot plots and separated into quadrants (Q1, Q2, Q3, Q4) by a vertical and a horizontal line that was set by eye, based on the blue and green fluorescence intensity from the cells (Fig. 1). Cell signals with low green fluorescence (no CFDA-AM fluorescence) remained below the horizontal line, as seen in the non-irradiated, unstained cells (Fig. 1b), and the sample UV irradiated with $800 \mathrm{~mJ} \mathrm{~cm}^{-2}$ (Fig. 1e). In contrast, CFDA-AM-stained cells with elevated green fluorescence appeared above the horizontal line, as shown in the non-irradiated, stained cells (Fig. 1a), and the sample UV irradiated with $200 \mathrm{~mJ} \mathrm{~cm}^{-2}$ (Fig. 1d). Similarly, the vertical line separates cells with low blue fluorescence (no SYTOX Blue fluorescence; Fig. 1a,b) from cells with elevated blue fluorescence (Fig. 1d). Interestingly, the sample UV irradiated with $200 \mathrm{~mJ} \mathrm{~cm}^{-2}$ appeared as $2 \mathrm{FCM}$ populations located above the horizontal line, but on both sides of the vertical line (Fig. 1c)

In general, cell signals from the non-irradiated, stained cells appeared in Q1 (Fig. 1a), whereas the non-irradiated, unstained cells appeared in Q3 (Fig. 1b). Also, UV-irradiated stained cells with remaining esterase activity appeared in Q1 and Q2 (Fig. 1C), while UV-irradiated stained cells without esterase activity appeared in Q4 and Q3 (Fig. 1d). Table 1 summarizes how intersections in the dot plots separate signals into 4 quadrants based on the staining characteristics of the cells.

\section{From live via damaged to dead cells}

Dot plots (Fig. 2) show a systematic progression of FCM signals as a function of time spent in the dark of 


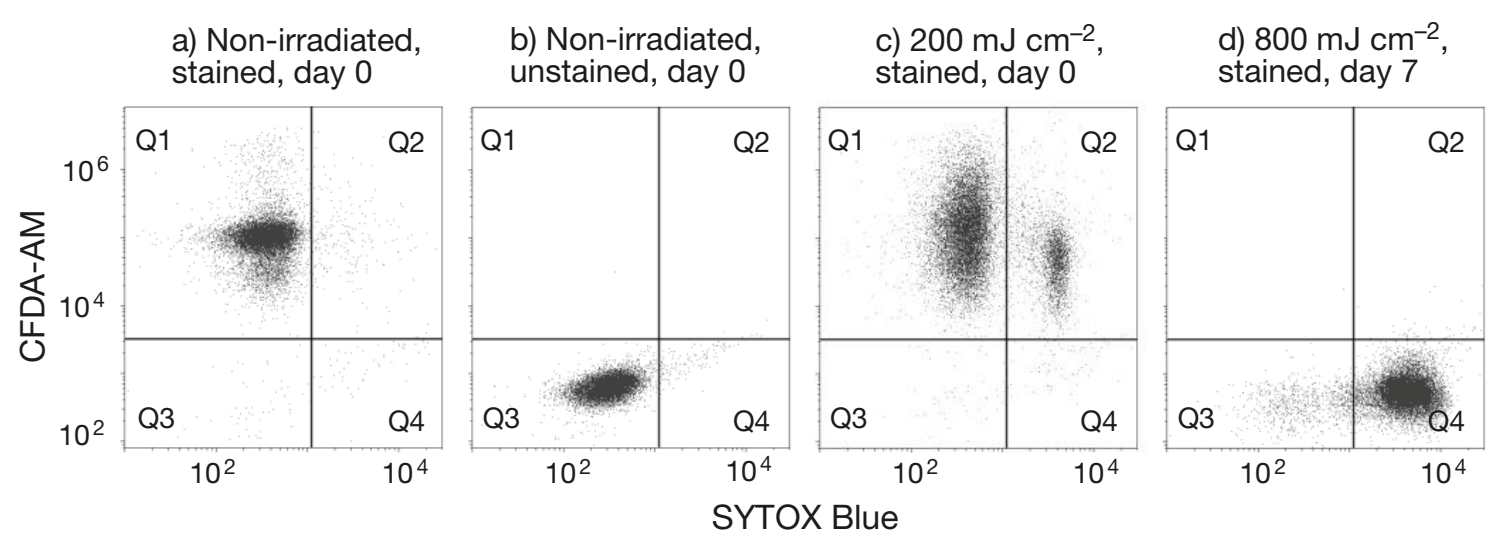

Fig. 1. Flow cytometry dot plots of Tetraselmis suecica cell signals plotted as coordinates of blue (SYTOX Blue) and green (CFDA-AM) fluorescence intensity for (a) non-irradiated, stained cells analyzed after $4 \mathrm{~h}$ of dark incubation, (b) non-irradiated, unstained cells analyzed after $4 \mathrm{~h}$ of dark incubation, (c) UV dose $200 \mathrm{~mJ} \mathrm{~cm}^{-2}$ analyzed $4 \mathrm{~h}$ after UV irradiation and dark incubation, and (d) UV dose $800 \mathrm{~mJ} \mathrm{~cm}^{-2}$ analyzed $7 \mathrm{~d}$ after UV irradiation and dark incubation. Intersections in the dot plots separate signals into 4 quadrants (Q1-Q4) based on the staining characteristics of the cells

Table 1. Overview of the quadrants (Q1-Q4) in response to elevated (+) or low (-) fluorescence intensity when cells were stained with CFDA-AM and SYTOX Blue. The quadrants reflect various physiological characteristics and vitality

\begin{tabular}{|lccll|}
\hline Quadrant & CFDA-AM & SYTOX Blue & Physiological characteristics & Vitality \\
\hline Q1 & + & - & Esterase active; membrane intact & Live \\
Q2 & + & + & Esterase active; membrane damaged & Severely damaged \\
Q3 & - & - & Esterase inactive; membrane intact or DNA/RNA degraded & Dead \\
Q4 & - & + & Esterase inactive; membrane damaged & Dead \\
\hline
\end{tabular}

non-irradiated, stained cells and cells irradiated with increasing UV doses. For the non-irradiated, stained cells most signals initially appeared in Q1 (live), gradually appearing in Q3 (dead) and further to Q4 (dead) during incubation, as a general trend. A few signals from single cells were observed in Q2 as well; however, these signals did not form a separate FCM population. Signals from the UV-irradiated samples followed a different pattern. This was already evident on Day 0, where signals appeared in Q2 after having been treated with the low UV doses and in Q4 after having irradiated the cells with the highest UV doses. The cells displayed a similar response to dark incubation; initially signals appeared in either Q1 or Q2 (depending on UV dose). During incubation, the signals disappeared from Q1/Q2 and appeared in Q2/Q4, respectively, and then signals entered into Q4. These trends are quantified in Fig. 3, showing the percentage of the FCM populations located in the different quadrants in the dot plots for the nonirradiated, stained cells and each of the UV-irradiated samples, as a function of time. The total amount of signals detected was $100 \%$. FCM signals from forward and side scatter remained in the same position in dot plots throughout the incubation period for all controls and UV-irradiated samples (data not shown). Red autofluorescence from chlorophyll was not reduced by high UV doses. However, chlorophyll fluorescence decreased during dark incubation, both for the non-irradiated and UV-irradiated samples. As the trigger on the flow cytometer was set to red fluorescence, the autofluorescence was still high enough so the cells could be detected and analyzed.

Some interesting observations were made for the UV-irradiated samples. (1) During incubation, a FCM population emerged in Q3, and was most prominent for samples treated with 300 and $400 \mathrm{~mJ} \mathrm{~cm}^{-2}$ (Fig. 2). This FCM population increased during dark incubation. (2) Some of the cells treated with low UV doses (100-200 mJ cm ${ }^{-2}$ ) exhibited elevated green fluorescence intensity in Q1 compared to the non-irradiated, stained cells (Fig. 2). (3) The most noteworthy observation is that the FCM population in Q2 (severely damaged) observed in UV-treated samples, was hardly present in the non-irradiated, stained cells. This FCM population (Q2) increased as a function of UV dose until reaching a dose of $800 \mathrm{~mJ} \mathrm{~cm}^{-2}$, where cells died almost immediately and appeared in Q4. For lower 


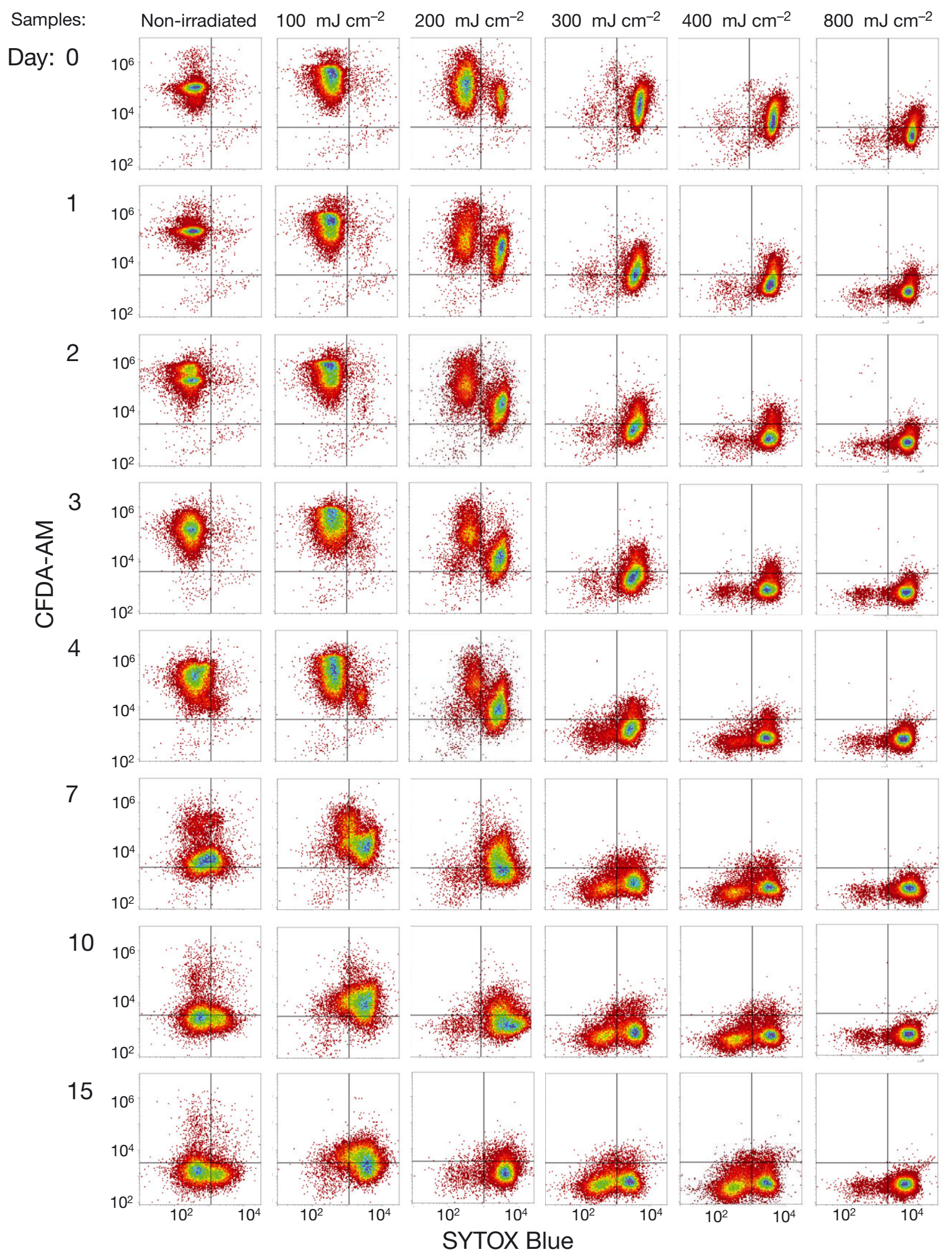

Fig. 2. Flow cytometry dot plots of Tetraselmis suecica stained with SYTOX Blue and CFDA-AM. Treatments (non-irradiated and various UV doses) are shown in the vertical columns and time of dark incubation in the horizontal rows. Intersections in the dot plots separate signals into 4 quadrants (see Fig. 1) 
a) Non-irradiated

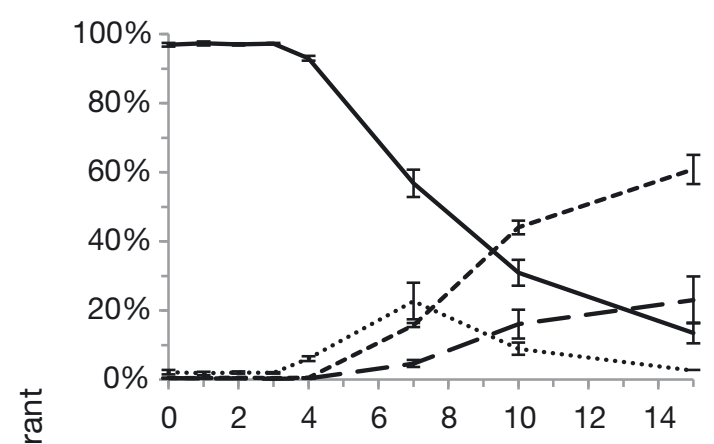

c) $200 \mathrm{~mJ} \mathrm{~cm}^{-2}$

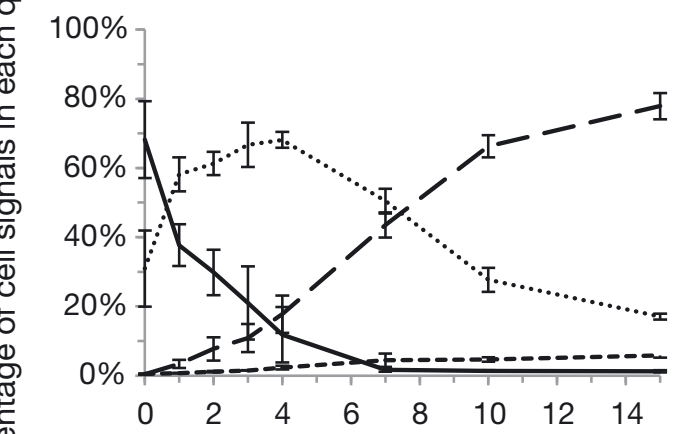

e) $400 \mathrm{~mJ} \mathrm{~cm}^{-2}$

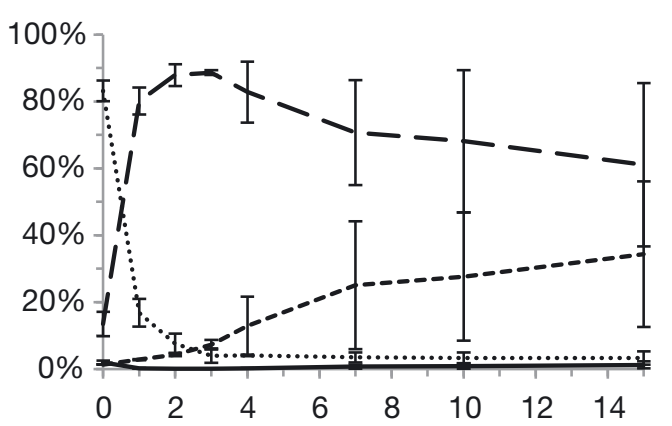

b) $100 \mathrm{~mJ} \mathrm{~cm}^{-2} \quad-\mathrm{Q} 1$

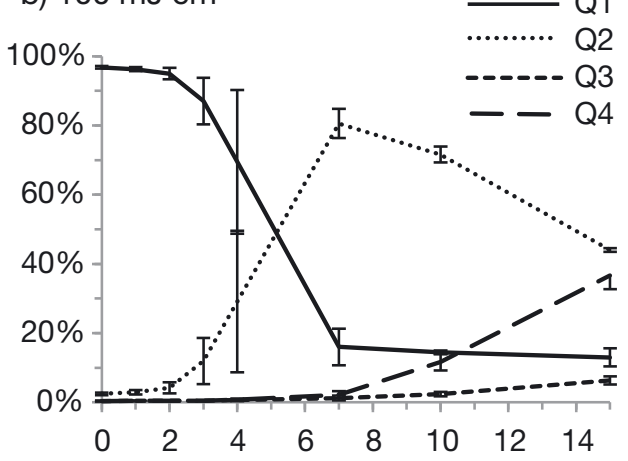

d) $300 \mathrm{~mJ} \mathrm{~cm}^{-2}$

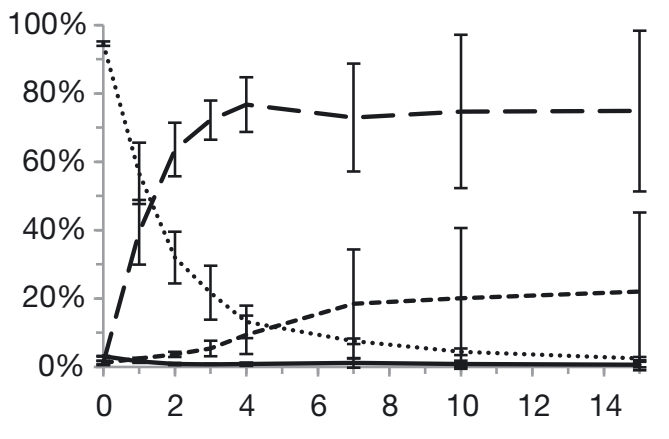

f) $800 \mathrm{~mJ} \mathrm{~cm}^{-2}$

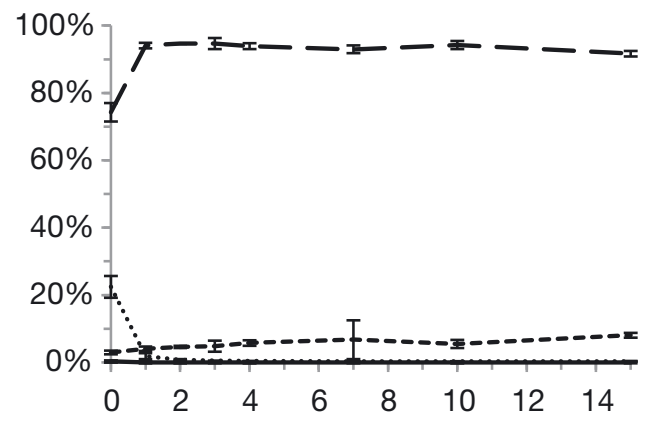

Days of dark incubation

Fig. 3. Percentage of cell signals after dark incubation from each quadrant for (a) the non-irradiated samples and (b-f) the samples UV treated with (b) 100, (c) 200, (d) 300, (e) 400, and (f) $800 \mathrm{~mJ} \mathrm{~cm}^{-2}$. Data are means of 3 replicates and error bars indicate \pm 1 SD. Q1-Q4 refer to the quadrants described in Fig. 1

UV doses, a similar pattern was observed during dark incubation; initially, the Q2 population increased, and when the cells died, the Q4 population increased (and Q2 was reduced accordingly).

\section{Plate count versus FCM}

Parallel to the FCM analysis, all samples were analyzed by plate count, as shown in Table 2. Although the number of reproducible cells (i.e. viable by defi- nition) in the non-irradiated samples was reduced by $96 \%$ after $15 \mathrm{~d}$ of dark incubation, some cells remained viable during the entire dark incubation period. The logarithmic concentration of culturable cells (as determined by cfu) was plotted versus time of dark incubation, and regression analyses were performed (Fig. 4a).

FCM signals appearing in Q1 are described as live (Table 1), although live cells can either be viable or non-viable. Therefore, in an attempt to quantify the number of viable cells in the FCM dot plot, the FCM 
Table 2. Numbers of flow cytometry (FCM) gated signals and $\mathrm{cfu}$ for the non-irradiated and UV-irradiated samples (100-800 $\mathrm{mJ} \mathrm{cm}^{-2}$ ) analyzed during dark incubation. Results are in cells $\mathrm{ml}^{-1}$. Data are the means $( \pm 1 \mathrm{SD})$ of 3 replicates

\begin{tabular}{|c|c|c|c|c|c|c|c|c|c|c|c|c|}
\hline \multirow[b]{2}{*}{ Day } & \multicolumn{2}{|c|}{ _Non-irradiated } & \multicolumn{2}{|c|}{$-100 \longrightarrow$} & \multicolumn{2}{|c|}{$-200-$} & \multicolumn{2}{|c|}{$-300-$} & \multicolumn{2}{|c|}{$-400-$} & \multicolumn{2}{|c|}{$-800-$} \\
\hline & $\mathrm{FCM}$ & $\mathrm{Cfu}$ & FCM & $\mathrm{Cfu}$ & FCM & Cfu & FCM & $\mathrm{Cfu}$ & FCM & $\mathrm{Cfu}$ & FCM & $\mathrm{Cfu}$ \\
\hline 0 & $12016( \pm 824)$ & $14133( \pm 2309)$ & $15039( \pm 1254)$ & $13600( \pm 608)$ & $7562( \pm 1894)$ & $1800( \pm 173)$ & $136( \pm 31)$ & $13( \pm 15)$ & $19( \pm 20)$ & $<10$ & $<10$ & $<10$ \\
\hline 1 & $12768( \pm 705)$ & $15067( \pm 2695)$ & $15244( \pm 360)$ & $1160( \pm 259)$ & $4010( \pm 233)$ & $167( \pm 115)$ & $9( \pm 6)$ & $<10$ & $<10$ & $<10$ & $<10$ & $<10$ \\
\hline 2 & $13011( \pm 1184)$ & 12467 & $14678( \pm 749)$ & $20( \pm 10)$ & $3132( \pm 983)$ & $33( \pm 58)$ & $<10$ & $<10$ & $<10$ & $<10$ & $<10$ & $<10$ \\
\hline 3 & $13454( \pm 191)$ & $6400( \pm 1709)$ & $12179( \pm 1583)$ & $7( \pm 6)$ & $1932( \pm 1219)$ & $<10$ & $<10$ & $<10$ & $<10$ & $<10$ & $<10$ & $<10$ \\
\hline 4 & $12001( \pm 628)$ & $2667( \pm 379)$ & $8517( \pm 4171)$ & $<10$ & $751( \pm 757)$ & $<10$ & $<10$ & $<10$ & $<10$ & $<10$ & $<10$ & $<10$ \\
\hline 7 & $1463( \pm 237)$ & $600( \pm 361)$ & $572( \pm 498)$ & $<10$ & $18( \pm 14)$ & $<10$ & $<10$ & $<10$ & $<10$ & $<10$ & $<10$ & $<10$ \\
\hline 10 & $579( \pm 163)$ & $400( \pm 173)$ & $51( \pm 23)$ & $<10$ & $<10$ & $<10$ & $<10$ & $<10$ & $<10$ & $<10$ & $<10$ & $<10$ \\
\hline 15 & $343( \pm 113)$ & $533( \pm 351)$ & $<10$ & $<10$ & $<10$ & $<10$ & $<10$ & $<10$ & $<10$ & $<10$ & $<10$ & $<10$ \\
\hline
\end{tabular}

cell signals were compared with the number of $\mathrm{cfu}$ (Fig. 4a). As previously described (Olsen et al. 2015), we defined a gate (= a collection of single cell signals) in the FCM dot plot based on the non-irradiated, stained sample (Fig. 5). The gate (Fig. 5) corresponds to the number of culturable cells determined by plate counts, and signals outside the gate originate from non-culturable cells. The logarithmic concentration of gated signals from FCM were plotted against time of dark incubation. Regression analyses were performed (Fig. 4b), and plate count regression (Fig. 4a) corresponded with FCM regression. a) Plate count

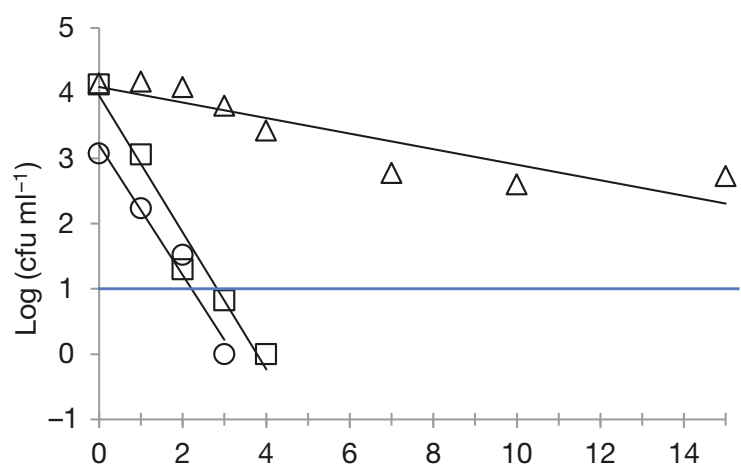

b) FCM

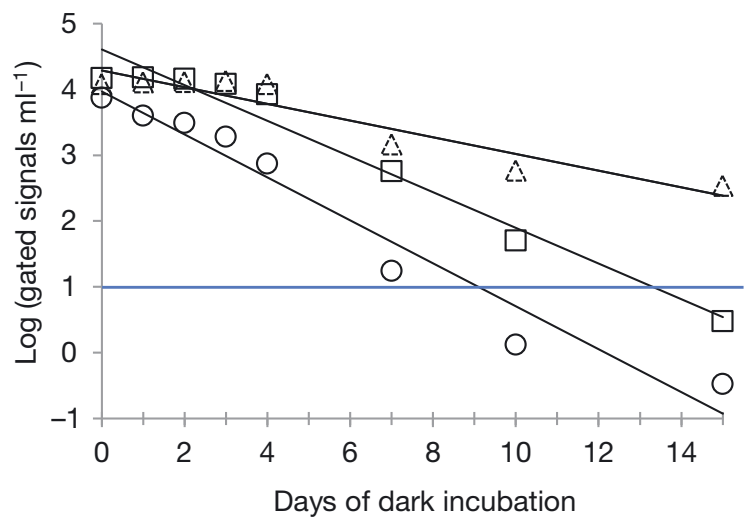

Non-irradiated: $y=-0.1193 x+4.0968$

$\mathrm{R}^{2}=0.8026$

P-value $=2.6 \times 10^{-3}$

$100 \mathrm{~mJ} \mathrm{~cm}^{-2}: \quad \mathrm{y}=-1.0508 \mathrm{x}+3.9661$

$R^{2}=0.963$

$\mathrm{P}$-value $=2.01 \times 10^{-2}$

$200 \mathrm{~mJ} \mathrm{~cm}^{-2}: \quad y=-0.9943 x+3.2007$

$R^{2}=0.9685$

$\mathrm{P}$-value $=2.85 \times 10^{-2}$

Fig. 4. Logarithmic declines in cell concentration of $\mathrm{cfu} \mathrm{ml}^{-1}$ from (a) plate counts and (b) the number of gated signals from flow cytometry, for the non-irradiated samples $(\Delta)$ and samples that were UV irradiated with $100(\square)$ and $200(O) \mathrm{mJ} \mathrm{cm}^{-2}$, during dark incubation. Data are the means of 3 replicates. The regression equations, $\mathrm{R}^{2}$, and $\mathrm{p}$-values for the non-irradiated and UVirradiated samples are given. The blue line indicates when the concentration of Tetraselmis suecica is $<10 \mathrm{cells}^{-1}$ and in compliance with Regulation D-2 (IMO 2004) 
a) Day 0

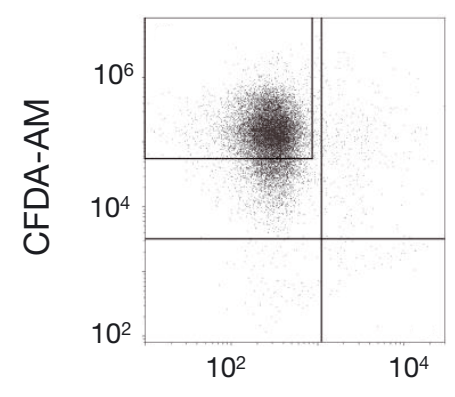

b) Day 3

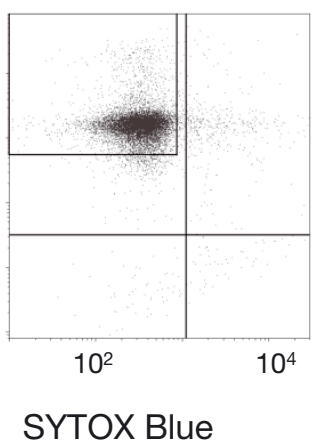

c) Day 10

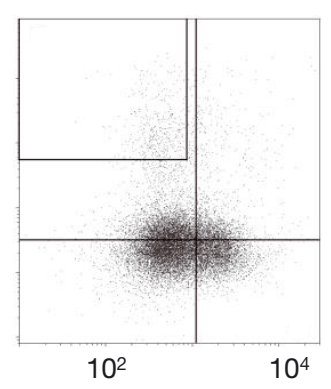

Fig. 5. Flow cytometry dot plot for non-irradiated samples after (a) $0 \mathrm{~d}(4 \mathrm{~h})$, (b) $3 \mathrm{~d}$, and (c) $10 \mathrm{~d}$ of dark incubation. The gate (box in quadrant 1) is based on the number of cfu. Therefore, signals inside the gate correspond to live, viable cells, whereas signals outside the gate correspond to live, non-viable cells

The gate was also applied to UV-irradiated samples to evaluate whether the FCM results correlated with the number of reproducible cells (cfu). For the samples UV irradiated with 100 and $200 \mathrm{~mJ} \mathrm{~cm}^{-2}$, the gated FCM signals were always higher than the cfu (Fig. 4a,b, respectively, and Table 2). For samples treated with UV doses $\geq 300 \mathrm{~mJ} \mathrm{~cm}^{-2}$, few or no cfu or gated signals were detected during the entire dark incubation period (Table 2).

\section{DISCUSSION}

UV irradiation can cause cell damage and change biochemical and/or physiological cellular characteristics, which can be studied with fluorescent dyes. We expected the FCM results from dual-stained (CFDA-AM and SYTOX Blue), non-irradiated cells to differ from dual-stained, UV-irradiated cells, since inactivation with UV light can affect both the esterase activity and membrane permeability in cells (Schenk et al. 2011). The FCM results did, indeed, demonstrate changes in these 2 physiological characteristics, which allowed separation of Tetraselmis suecica into $4 \mathrm{FCM}$ populations after dual staining of non-irradiated and UV-irradiated samples. The quadrants and physiological characteristics reflect the vitality, i.e. whether the cell is live, severely damaged, or dead.

Similar observations have been described for bacterial populations dual stained with esterase substrates (CFDA/FDA) and PI, viz. in bile-salt-stressed bifidobacterial cells (Ben Amor et al. 2002), ethanolstressed malolactic cells (da Silveira et al. 2002), pressure-stressed Lactobacillus rhamnosus (Ananta et al. 2004, 2005, Ananta \& Knorr 2009), UV-C-irradial. 2009, Hammes et al. 2011). The membranes of Saccharomyces cerevisiae developed a transient permeability to PI during and immediately following exposure to physical (heat) and chemical (ethanol) stress, but then repaired the damage after a short incubation period (Davey \& Hexley 2011). However, since yeast cells do not use light as an energy source, light/dark conditions do not affect repair. Hence, it was important to examine the further development of the cell membrane damaged FCM populations (Q2) in UV-irradiated $T$. suecica samples.

During dark incubation, the esterase activity of the non-irradiated (live) cells decreased, and this was later followed by a loss of membrane integrity. Darkness affects the vitality/viability of phytoplankton over time (Jochem 1999), since light limitation deprives cells of the principal energy source for maintenance, including the support of the integrity of the plasma membrane (Berges \& Falkowski 1998). Further, phytoplankton can undergo programmed cell death in response to environmental stress (Bidle \& Falkowski 2004, Franklin et al. 2006, Bidle 2015), such as light deprivation (Berges \& Falkowski 1998, Segovia et al. 2003, Segovia \& Berges 2009). Loss of membrane integrity during incubation can also be caused by natural degradation processes (Davey 2011). However, phytoplankton have survival strategies when exposed to unfavorable conditions (Jochem 1999, 2000, Hallegraeff 2010). For ballast water, the voyage duration affects organism survival, although photosynthetic organisms can survive several weeks in darkness (Peters 1996, Jochem 1999, Carney et al. 2011). Therefore, ballast water needs to be treated.

The T. suecica samples treated with UV irradiation showed a different pattern in FCM dot plots, as 
the cells lost their membrane integrity immediately after treatment and as a response to the UV dose applied. This indicates that even low UV doses cause membrane disruption. High UV irradiation may increase membrane permeability (Sobrino et al. 2004), but also target plant membrane lipids, proteins, and their complexes (Murphy 1983), affect human cell membrane receptors inducing programmed cell death (Schwarz 1998, Kulms et al. 1999, Franklin et al. 2006), and/or enhance ROS production, potentially causing oxidative damage to lipids and impair membrane transport in bacteria (Santos et al. 2012, 2013).

Reduction in esterase activity during dark incubation was greater for the UV-irradiated cells than nonirradiated ones, as previously demonstrated (Olsen et al. 2015). For the samples UV irradiated with 100 and $200 \mathrm{~mJ} \mathrm{~cm}{ }^{-2}, 2 \mathrm{FCM}$ populations of cells with esterase activity were observed (in Q1 and Q2), indicating heterogeneity within the samples. It has been argued that a decrease in fluorescence from carboxyfluorescein ( $\mathrm{CF}$, hydrolyzed esterase substrate) may occur as a result of leakage due to a damaged membrane rather than inactivated enzymes (Kramer \& Muranyi 2014), and that cells with severely damaged membranes thus would reduce their cell size (Ou et al. 2012). As CF has negative charges at physiological pH (Breeuwer \& Abee 2000), this may partially inhibit its leakage from damaged cells, unless a certain degree of membrane degradation is exceeded. However, our forward and side scatter results implied that the cells maintained their size during the analysis period. This indicates that membrane damage did not cause leakage, and the observed decrease in green fluorescence is therefore most likely caused by inactivated enzymes. CFDA-AM is therefore a good indicator to evaluate metabolic activity in UV-irradiated T. suecica.

Interestingly, some cells irradiated with low UV doses (100-200 $\mathrm{mJ} \mathrm{cm}^{-2}$ ) showed higher green fluorescence intensity (Q1) compared to the nonirradiated cells. Stains can be actively secreted from active organisms by an energy-dependent process, as shown for efflux of fluorescein and fluorescein derivatives in Lactococcus lactis and S. cerevisiae (Molenaar et al. 1991, 1992, Breeuwer et al. 1994). Because of the negatively charged $\mathrm{CF}$, passive transport is unlikely (Martin \& Lindqvist 1975). UV light can cause loss of membrane potential, often occurring before loss of membrane integrity, and this can cause loss of efflux pump activity, as shown in UV-A irradiated and/or pulsed light-treated (UV) E. coli, Salmonella typhimurium, and Shigella flexneri (Berney et al. 2006, Bosshard et al. 2009, Kramer \& Muranyi 2014). If efflux pumps are damaged by UV, CF might accumulate to higher concentrations in UV-irradiated cells compared to non-irradiated ones. Elevated green fluorescence intensity from dual-stained cells treated with low UV doses can thus be a sign of cellular damage and reduced membrane potential.

An FCM population of UV-irradiated cells with low green and blue fluorescence (Q3) emerged after prolonged incubation. These cells demonstrated elevated blue fluorescence initially, indicating that the cells were already dead. The loss of blue fluorescence can be explained by degraded DNA/RNA as part of the cellular degradation process, which results in fewer/no possible binding sites for SYTOX Blue (Davey 2011). Therefore, cells in Q3 and Q4 are considered dead with damaged membranes in both FCM populations. This further demonstrates that SYTOX Blue is not an ideal stain to use as a single dye in long-term studies of UV-irradiated cells, as dead cells are not always detectable.

Our results show that UV irradiation caused a loss of membrane integrity prior to the loss of esterase activity. This is evident in the FCM population with elevated green and blue fluorescence (Q2), as also demonstrated in other studies with bacteria as target organisms (Ben Amor et al. 2002, da Silveira et al. 2002, Ananta et al. 2004, 2005, Ananta \& Knorr 2009, Schenk et al. 2011, Zhao et al. 2011, Hong et al. 2015). The esterase substrate CFDA-AM was selected since both IMO and USCG have performance standards for concentrations of living cells at ballast water discharge (IMO 2004, USCG 2012). The esterase activity in the severely damaged cells (Q2) was further reduced during incubation, i.e. the cells were injured to such a degree that they would eventually die. Some studies have denoted FCM populations containing esterase activity but with damaged membranes, as sub-lethally injured cells (Ananta et al. 2004, Zhao et al. 2011, Hong et al. 2015). Consequently, simultaneous green and blue fluorescent signals can detect these sub-lethal/dying cells and by this indicate future death.

The MPN method was recently rejected by the USCG. It is not considered equivalent to the USCG preferred vital stain method for the 10-50 $\mu \mathrm{m}$ size class since it assesses the ability of an organism to recolonize after treatment, and BWTS must be evaluated based on their ability to kill certain organisms. Growth-based methods, like plate counts and MPN, can be time consuming, especially for slow-growing species. The number of organisms in a sample can be underestimated due to selective growth media and 
individual growth requirements, and many species cannot even be grown in a laboratory. The FCM protocol presented here does not rely on cultivation, gives information of the vitality of the cells in a sample as preferred by the USCG, and allows for faster analysis (and hence reduced fading of the staining) and analysis of larger volumes compared to microscopy.

To investigate the interrelationship between live cells (esterase active cells with intact membranes) and reproducibility, the FCM results were compared with plate count results, as cfu represents cells with the ability to grow and reproduce. Reasons explaining the discrepancies between reproducibility and physiological characteristics, as well as the possibility that the gate includes some non-culturable cells for the UV-irradiated samples, have previously been discussed (Olsen et al. 2015). Plate count and the gated FCM results for the non-irradiated samples showed that there were viable cells left after $15 \mathrm{~d}$ of dark incubation. This indicates that some cells survive in darkness, explained by cells adapting to prolonged periods of darkness (Jochem 1999, Carney et al. 2011). When using FCM and the dual staining protocol (CFDA-AM and SYTOX Blue) developed in this study, cells with severe membrane damage after UV irradiation are excluded from the reproducible cells gate. This is an improvement compared to our previously developed FCM protocol, where staining with only CFDA-AM did not exclude cells with membrane damage. Consequently, quantification of reproducible cells with the FCM dual-staining protocol is more in accordance with results from the plate count method. In this study, the $T$. suecica culture was irradiated with an MP UV lamp, representing a small-scale BWTS. Our study was conducted with this organism only, as a representative of the $\geq 10-50 \mu \mathrm{m}$ size categories of marine organisms in Regulation D-2 for fulfilling the biological water quality criteria for approval of BWTS (IMO 2008). The species is not as common as diatoms, dinoflagellates, and prymnesiophytes in coastal waters, and although the dualstaining protocol proved well suited for type approval, its full potential remains to be examined on the diverse community of organisms that will be encountered in ships' ballasting practices. One disadvantage of using FCM in compliance testing is the difficulty of minimum dimension (the smallest part of the body) measurements, since FCM can more easily detect maximum dimension of organisms. The T. suecica culture used in this study consisted of live cells with high enzymatic activity. In natural water, the phytoplankton community is diverse and will vary with location, season, and environmental conditions. The level of activity can vary between species, and they may have different tolerances to environmental changes and disinfection treatments (Jochem 1999, 2000, Olsen et al. 2015). Additionally, algae can develop resting stages, like cysts, with low activity levels (Hallegraeff 2010). Even though the majority of phytoplankton species are detectable by the esterase substrates 5-chloromethylfluorescein diacetate and fluorescein diacetate, we are aware that fluorescence intensity from esterase substrates can vary over a range in living cells (Peperzak \& Brussaard 2011). Therefore, the esterase activity in organisms in natural water samples should be examined further. Moreover, biotic and abiotic particles in seawater can influence the inactivation efficiency by protecting the microbes during UV irradiation (HessErga et al. 2008, Tang et al. 2011). Normally, a commercial BWTS comprises 2 or more treatment stages, in contrast to the sole UV lamp used in our experiment, possibly enhancing the inactivation efficiency (Lloyd's Register Marine 2015). However, UV irradiation is a disinfection method that can cause delayed mortality in cells, and our FCM detection method is well suited for analysis of $T$. suecica processed by a UV-based BWTS.

\section{CONCLUSIONS}

Combining SYTOX Blue and CFDA-AM facilitates and improves FCM analysis to evaluate the performance of UV-based water treatment systems, and the FCM protocol allows differentiation into live, damaged, and dead Tetraselmis suecica cells, not only live and dead. The damaged cells are prone to die under dark incubation. The protocol can be used for type approval of UV-based BWTS when T. suecica is included in the test water as a representative for the 10-50 $\mu \mathrm{m}$ size group. Further, the dual-staining FCM protocol has the potential to be used for detailed compliance testing, although further research is required.

Acknowledgements. This research was funded by the Norwegian Research Council (project BallastFlow, project no. 208653) and Knutsen OAS Shipping AS, and supported by Solstad Shipping, Stord/Haugesund University College, VRI Rogaland, UH-nett Vest, and TeknoVest. We thank Stephanie Delacroix, August Tobiesen (Norwegian Institute for Water Research, Oslo, Norway), and Per Lothe (Knutsen OAS Shipping AS, Haugesund, Norway) for helpful discussions. 


\section{LITERATURE CITED}

Ananta E, Knorr D (2009) Comparison of inactivation pathways of thermal or high pressure inactivated Lactobacillus rhamnosus ATCC 53103 by flow cytometry analysis. Food Microbiol 26:542-546

Ananta E, Heinz V, Knorr D (2004) Assessment of high pressure induced damage on Lactobacillus rhamnosus GG by flow cytometry. Food Microbiol 21:567-577

> Ananta E, Voigt D, Zenker M, Heinz V, Knorr D (2005) Cellular injuries upon exposure of Escherichia coli and Lactobacillus rhamnosus to high-intensity ultrasound. J Appl Microbiol 99:271-278

> Ben Amor KB, Breeuwer P, Verbaarschot P, Rombouts FM, Akkermans ADL, De Vos WM, Abee T (2002) Multiparametric flow cytometry and cell sorting for the assessment of viable, injured, and dead Bifidobacterium cells during bile salt stress. Appl Environ Microbiol 68:5209-5216

Bentley-Mowat JA (1982) Application of fluorescence microscopy to pollution studies on marine phytoplankton. Bot Mar 25:203-204

> Berges JA, Falkowski PG (1998) Physiological stress and cell death in marine phytoplankton: induction of proteases in response to nitrogen or light limitation. Limnol Oceanogr 43:129-135

> Berney M, Weilenmann HU, Egli T (2006) Flow-cytometric study of vital cellular functions in Escherichia coli during solar disinfection (SODIS). Microbiology (Read) 152: 1719-1729

Berney M, Hammes F, Bosshard F, Weilenmann HU, Egli T (2007) Assessment and interpretation of bacterial viability by using the LIVE/DEAD BacLight kit in combination with flow cytometry. Appl Environ Microbiol 73: 3283-3290

Bidle KD (2015) The molecular ecophysiology of programmed cell death in marine phytoplankton. Annu Rev Mar Sci 7:341-375

Bidle KD, Falkowski PG (2004) Cell death in planktonic, photosynthetic microorganisms. Nat Rev Microbiol 2: 643-655

> Bosshard F, Berney M, Scheifele M, Weilenmann HU, Egli T (2009) Solar disinfection (SODIS) and subsequent dark storage of Salmonella typhimurium and Shigella flexneri monitored by flow cytometry. Microbiology (Read) 155: 1310-1317

Bosshard F, Riedel K, Schneider T, Geiser C, Bucheli M, Egli T (2010) Protein oxidation and aggregation in UVAirradiated Escherichia coli cells as signs of accelerated cellular senescence. Environ Microbiol 12:2931-2945

- Breeuwer P, Abee T (2000) Assessment of viability of microorganisms employing fluorescence techniques. Int J Food Microbiol 55:193-200

> Breeuwer P, Drocourt JL, Rombouts FM, Abee T (1994) Energy-dependent, carrier-mediated extrusion of carboxyfluorescein from Saccharomyces cerevisiae allows rapid assessment of cell viability by flow cytometry. Appl Environ Microbiol 60:1467-1472

> Brookes JD, Geary SM, Ganf GG, Burch MD (2000) Use of FDA and flow cytometry to assess metabolic activity as an indicator of nutrient status in phytoplankton. Mar Freshw Res 51:817-823

Carney KJ, Delany JE, Sawant S, Mesbahi E (2011) The effects of prolonged darkness on temperate and tropical marine phytoplankton, and their implications for ballast water risk management. Mar Pollut Bull 62:1233-1244
Chen RZ, Craik SA, Bolton JR (2009) Comparison of the action spectra and relative DNA absorbance spectra of microorganisms: information important for the determination of germicidal fluence (UV dose) in an ultraviolet disinfection of water. Water Res 43:5087-5096

da Silveira MG, San Romao MV, Loureiro-Dias MC, Rombouts FM, Abee T (2002) Flow cytometric assessment of membrane integrity of ethanol-stressed Oenococcus oeni cells. Appl Environ Microbiol 68:6087-6093

$>$ Davey HM (2011) Life, death, and in-between: meanings and methods in microbiology. Appl Environ Microbiol 77:5571-5576

D Davey HM, Hexley P (2011) Red but not dead? Membranes of stressed Saccharomyces cerevisiae are permeable to propidium iodide. Environ Microbiol 13:163-171

Dorsey J, Yentsch CM, Mayo S, McKenna C (1989) Rapid analytical technique for the assessment of cell metabolic activity in marine microalgae. Cytometry 10:622-628

Franklin DJ, Brussaard CPD, Berges JA (2006) What is the role and nature of programmed cell death in phytoplankton ecology? Eur J Phycol 41:1-14

Franklin NM, Adams MS, Stauber JL, Lim RP (2001) Development of an improved rapid enzyme inhibition bioassay with marine and freshwater microalgae using flow cytometry. Arch Environ Contam Toxicol 40:469-480

Ganassin RC, Schirmer K, Bols NC (2000) Cell and tissue culture. In: Ostrander GK (ed) The laboratory fish. Academic Press, London, p 631-651

Garvey M, Moriceau B, Passow U (2007) Applicability of the FDA assay to determine the viability of marine phytoplankton under different environmental conditions. Mar Ecol Prog Ser 352:17-26

> Gorokhova E, Mattsson L, Sundström AM (2012) A comparison of TO-PRO-1 iodide and 5-CFDA-AM staining methods for assessing viability of planktonic algae with epifluorescence microscopy. J Microbiol Methods 89: 216-221

Hallegraeff GM (2010) Ocean climate change, phytoplankton community responses, and harmful algal blooms: a formidable predictive challenge. J Phycol 46:220-235

Hammes F, Berney M, Egli T (2011) Cultivation-independent assessment of bacterial viability. In: Müller S, Bley T (eds) High resolution microbial single cell analytics, Vol 124. Springer, Berlin and Heidelberg, p 123-150

> Hess-Erga OK, Kihle Attramadal KJ, Vadstein O (2008) Biotic and abiotic particles protect marine heterotrophic bacteria during UV and ozone disinfection. Aquat Biol 4: 147-154

Hong J, Guan W, Jin G, Zhao H, Jiang X, Dai J (2015) Mechanism of tachyplesin I injury to bacterial membranes and intracellular enzymes, determined by laser confocal scanning microscopy and flow cytometry. Microbiol Res 170:69-77

IMO (International Maritime Organization) (2004) International convention for the control and management of ships' ballast water and sediments. International Maritime Organization, London

IMO (2008) Guidelines for approval of ballast water management systems (G8). Marine Environment Protection Committee, Resolution MEPC.174(58), 10 October 2008. International Maritime Organization, London

Jochem FJ (1999) Dark survival strategies in marine phytoplankton assessed by cytometric measurement of metabolic activity with fluorescein diacetate. Mar Biol 135: $721-728$ 
Jochem FJ (2000) Probing the physiological state of phytoplankton at the single-cell level. Sci Mar 64:183-195

> Joux F, Lebaron P (2000) Use of fluorescent probes to assess physiological functions of bacteria at single-cell level. Microbes Infect 2:1523-1535

Kalisvaart BF (2001) Photobiological effects of polychromatic medium pressure UV lamps. Water Sci Technol 43: 191-197

Kottuparambil S, Shin W, Brown MT, Han T (2012) UV-B affects photosynthesis, ROS production and motility of the freshwater flagellate, Euglena agilis Carter. Aquat Toxicol 122-123:206-213

> Kramer B, Muranyi P (2014) Effect of pulsed light on structural and physiological properties of Listeria innocua and Escherichia coli. J Appl Microbiol 116:596-611

Kroemer G, Galluzzi L, Vandenabeele P, Abrams J and others (2009) Classification of cell death: recommendations of the Nomenclature Committee on Cell Death 2009. Cell Death Differ 16:3-11

> Kulms D, Poppelmann B, Yarosh D, Luger TA, Krutmann J, Schwarz T (1999) Nuclear and cell membrane effects contribute independently to the induction of apoptosis in human cells exposed to UVB radiation. Proc Natl Acad Sci USA 96:7974-7979

Lloyd's Register Marine (2015) Understanding ballast water management. Guidance for shipowners and operators. Lloyd's, London

> Martin MM, Lindqvist L (1975) The pH dependence of fluorescein fluorescence. J Lumin 10:381-390

> Martínez LF, Mahamud MM, Lavín AG, Bueno JL (2012) Evolution of phytoplankton cultures after ultraviolet light treatment. Mar Pollut Bull 64:556-562

> Molenaar D, Abee T, Konings WN (1991) Continuous measurement of the cytoplasmic $\mathrm{pH}$ in Lactococcus lactis with a fluorescent $\mathrm{pH}$ indicator. Biochim Biophys Acta 1115: 75-83

Molenaar D, Bolhuis H, Abee T, Poolman B, Konings WN (1992) The efflux of a fluorescent probe is catalyzed by an ATP-driven extrusion system in Lactococcus lactis. J Bacteriol 174:3118-3124

- Murphy TM (1983) Membranes as targets of ultraviolet radiation. Physiol Plant 58:381-388

> Murphy AM, Cowles TJ (1997) Effects of darkness on multiexcitation in vivo fluorescence and survival in a marine diatom. Limnol Oceanogr 42:1444-1453

> Olsen RO, Hess-Erga OK, Larsen A, Thuestad G, Tobiesen A, Hoell IA (2015) Flow cytometric applicability to evaluate UV inactivation of phytoplankton in marine water samples. Mar Pollut Bull 96:279-285

> Olsen RO, Hoffmann F, Hess-Erga OK, Larsen A, Thuestad G, Hoell IA (2016) Ultraviolet radiation as a ballast water treatment strategy: inactivation of phytoplankton measured with flow cytometry. Mar Pollut Bull 103:270-275

Ou H, Gao N, Deng Y, Qiao J, Wang H (2012) Immediate and long-term impacts of UV-C irradiation on photosynthetic capacity, survival and microcystin-LR release risk of Microcystis aeruginosa. Water Res 46:1241-1250

> Peperzak L, Brussaard CPD (2011) Flow cytometric applicability of fluorescent vitality probes on phytoplankton. J Phycol 47:692-702

> Peperzak L, Gollasch S (2013) NIOZ flow cytometer workshop, comparing organism detection instruments in measuring 2-10 $\mu \mathrm{m}$ and $10-50 \mu \mathrm{m}$ plankton cells. Final report, prepared for Interreg IVB project Ballast Water Opportunity
Peters E (1996) Prolonged darkness and diatom mortality: II. Marine temperate species. J Exp Mar Biol Ecol 207: 43-58

Roszak DB, Colwell RR (1987) Survival strategies of bacteria in the natural environment. Microbiol Rev 51:365-379

Santos AL, Gomes NCM, Henriques I, Almeida A, Correia A, Cunha Â (2012) Contribution of reactive oxygen species to UV-B-induced damage in bacteria. J Photochem Photobiol B 117:40-46

Santos AL, Oliveira V, Baptista I, Henriques I and others (2013) Wavelength dependence of biological damage induced by UV radiation on bacteria. Arch Microbiol 195: 63-74

Schenk M, Raffellini S, Guerrero S, Blanco GA, Alzamora SM (2011) Inactivation of Escherichia coli, Listeria innocua and Saccharomyces cerevisiae by UV-C light: study of cell injury by flow cytometry. Lebensm Wiss Technol 44: 191-198

Schwarz T (1998) UV light affects cell membrane and cytoplasmic targets. J Photochem Photobiol B 44:91-96

Segovia M, Berges JA (2009) Inhibition of caspase-like activities prevents the appearance of reactive oxygen species and dark-induced apoptosis in the unicellular chlorophyte Dunaliella tertiolecta. J Phycol 45:1116-1126

Segovia M, Haramaty L, Berges JA, Falkowski PG (2003) Cell death in the unicellular chlorophyte Dunaliella tertiolecta. A hypothesis on the evolution of apoptosis in higher plants and metazoans. Plant Physiol 132:99-105

Shannon MA, Bohn PW, Elimelech M, Georgiadis JG, Marinas BJ, Mayes AM (2008) Science and technology for water purification in the coming decades. Nature 452: 301-310

Shapiro HM (1983) Multistation multiparameter flow cytometry: a critical review and rationale. Cytometry 3:227-243

> Shapiro HM (2000) Microbial analysis at the single-cell level: tasks and techniques. J Microbiol Methods 42:3-16

Shi L, Gunther S, Hubschmann T, Wick LY, Harms H, Muller S (2007) Limits of propidium iodide as a cell viability indicator for environmental bacteria. Cytometry 71A:592-598

Sinha RP, Häder DP (2002) UV-induced DNA damage and repair: a review. Photochem Photobiol Sci 1:225-236

Sobrino C, Montero O, Lubián L (2004) UV-B radiation increases cell permeability and damages nitrogen incorporation mechanisms in Nannochloropsis gaditana. Aquat Sci 66:421-429

Spence MTZ, Johnson ID (2010) The molecular probes handbook: a guide to fluorescent probes and labeling technologies, Vol 11. Life Technologies Corporation

Staley JT, Konopka A (1985) Measurement of in situ activities of nonphotosynthetic microorganisms in aquatic and terrestrial habitats. Annu Rev Microbiol 39:321-346

> Steinberg MK, Lemieux EJ, Drake LA (2011) Determining the viability of marine protists using a combination of vital, fluorescent stains. Mar Biol 158:1431-1437

> Steinberg MK, First MR, Lemieux EJ, Drake LA and others (2012) Comparison of techniques used to count singlecelled viable phytoplankton. J Appl Phycol 24:751-758

Tang KW, Dziallas C, Grossart HP (2011) Zooplankton and aggregates as refuge for aquatic bacteria: protection from UV, heat and ozone stresses used for water treatment. Environ Microbiol 13:378-390

USCG (United States Coast Guard) (2012) Standards for living organisms in ships' ballast water discharged in U.S. waters. USCG Federal Register, Department of 
Homeland Security

> Veldhuis MJW, Cucci TL, Sieracki ME (1997) Cellular DNA content of marine phytoplankton using two new fluorochromes: taxonomic and ecological implications. J Phycol 33:527-541

Werschkun B, Sommer Y, Banerji S (2012) Disinfection byproducts in ballast water treatment: an evaluation of regulatory data. Water Res 46:4884-4901

Werschkun B, Banerji S, Basurko OC, David M and others (2014) Emerging risks from ballast water treatment: the run-up to the international ballast water management

Editorial responsibility: Brant Touchette, Elon, North Carolina, USA convention. Chemosphere 112:256-266

Xiao X, Han ZY, Chen YX, Liang XQ, Li H, Qian YC (2011) Optimization of FDA-PI method using flow cytometry to measure metabolic activity of the cyanobacteria, Microcystis aeruginosa. Phys Chem Earth 36:424-429

Zhao W, Yang R, Zhang HQ, Zhang W, Hua X, Tang Y (2011) Quantitative and real time detection of pulsed electric field induced damage on Escherichia coli cells and sublethally injured microbial cells using flow cytometry in combination with fluorescent techniques. Food Contr 22:566-573

Submitted: March 2, 2016; Accepted: July 14, 2016 Proofs received from author(s): August 5, 2016 